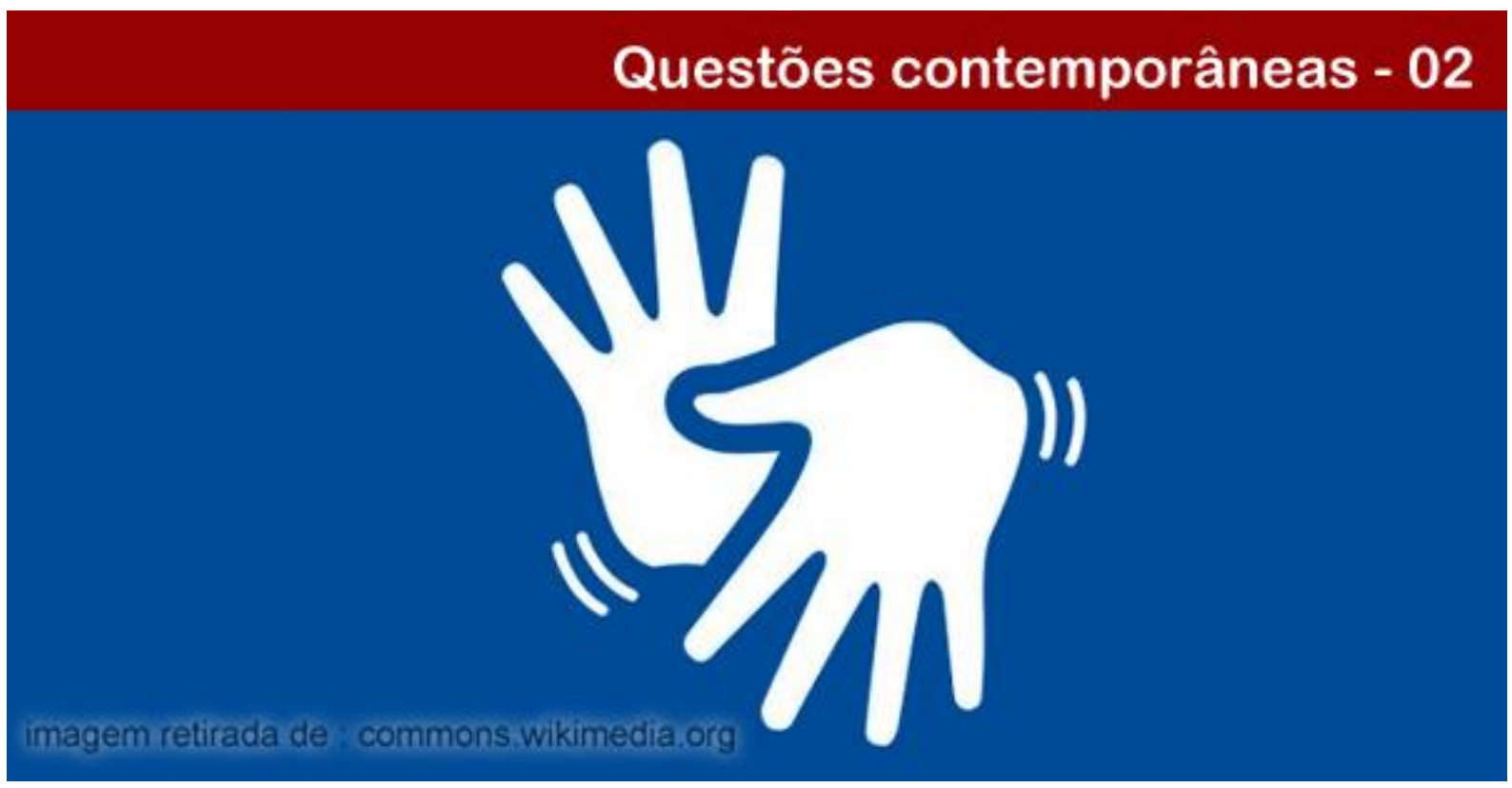

\title{
INFORMAÇÃO PARA E PELOS SURDOS: SOBRE TRANSMISSÃO AUDIOVISUAL EM LIBRAS E DESENVOLVIMENTO DA CRITICIDADE
}

\author{
Jaciara de Sá Carvalho \\ Professora adjunta no Programa de Pós-Graduação em Educação da Universidade Estácio de Sá (UNESA). \\ Doutora e mestre em Educação pela Universidade de São Paulo (USP). Especialista em Gestão de Processos de \\ Comunicação/Educomunicação pela USP. E-mail: jsacarvalho@gmail.com.
}

\section{Rita de Cássia Martins da Costa Brito}

Instituto Nacional de Educação de Surdos (INES). Mestre em Educação e graduada em Comunicação Social pela Universidade Estácio de Sá(UNESA). E-mail: ritamartins2001 @ gmail.com.

Resumo: Cerca de 5\% da população brasileira possui algum grau de perda de audição (IBGE, 2010). São dez milhões de brasileiros com dificuldades de acesso às informações sobre as realidades de seu país e do mundo, ao conhecimento sistematizado pelas ciências etc. Alguns programas audiovisuais recorrem a legendas em Português e/ou intérpretes da Língua Brasileira de Sinais - Libras, atuando nas chamadas "janelinhas", sendo exceção os produzidos por profissionais surdos e apresentados por eles em primeiro plano na tela. Sob tal contexto de discussão, e partindo da premissa da formação humana ao longo da vida, este artigo apresenta uma problematização acerca das diferenças entre a transmissão de informações por surdos e por intérpretes a partir de pesquisa bibliográfica. O trabalho sugere que uma informação transmitida de surdo para surdo, em audiovisuais, estaria mais próxima ao conteúdo original da mensagem e ao universo linguístico e cultural das comunidades Surdas. Também expõe uma reflexão sobre a necessidade de ampliação do repertório informacional para o desenvolvimento (permanente) da consciência crítica (FREIRE, 1979) pelos surdos que anseiam "ser mais".

Palavras-chave: Surdez. Libras. Acesso à informação.

\section{INFORMATION FOR AND BY THE DEAF: ON THE AUDIOVISUAL TRANSMISSION BY LIBRAS AND THE CRITICAL DEVELOPMENT}

Abstract: About 5\% of the Brazilian population has some degree of hearing loss (IBGE, 2010). There are ten million Brazilians who have difficulty accessing information about the realities of their country and of the world, knowledge drawn up by the sciences, etc. Some audiovisual programs use Portuguese subtitles and/or Brazilian Sign Language interpreters (Libras) acting in their little "windows" as they are called, with the exception of those

\section{POLÊM!CA $\mid$ LABORE}

Polêmica - Revista Eletrônica da Uerj - Rua São Francisco Xavier, 524, $1^{\circ}$ andar bloco D, sl.1001 • Tels.: +55 21 2334-4088 / 4087 • http://www.e-publicacoes.uerj.br/index.php/polemica/index http://www.labore.uerj.br • laboreuerj@yahoo.com.br 
produced by deaf professionals and presented to them in the foreground of the screen. Under this context of discussion, and based on the premise of human lifelong training, this article presents an examination of the differences between the transmission of information by deaf people and by interpreters, based on bibliographic research. The paper points out that information transmitted from deaf to deaf in audiovisuals would be closer to the original content of the message, and to the linguistic and cultural universe of the deaf community. It also presents a reflection on the need to expand the informational repertoire for the (permanent) development of critical consciousness (FREIRE, 1979) by deaf people who yearn to "be more."

Keywords: Deafness. Libras. Access to information.

\section{Introdução}

O último censo do Instituto Brasileiro de Geografia e Estatística (IBGE, 2010) informa que $23,9 \%$ da população apresenta algum tipo de deficiência; desse total, 5\% das pessoas possuem algum grau de perda de audição. São dez milhões de brasileiros que enfrentam dificuldades de acesso às informações sobre serviços, notícias de seu país e do mundo, ao conhecimento sistematizado pelas ciências, etc.

No país, existem leis para tentar garantir o uso e a difusão da língua mais utilizada pelos surdos. A Lei $\mathrm{n}^{\circ} 10.436$ (BRASIL, 2002), chamada Lei de Libras, é uma das mais importantes por reconhecer a Língua Brasileira de Sinais como a língua oficial das comunidades Surdas ${ }^{1}$ brasileiras e, volta-se, principalmente, para o sistema educacional e o de saúde. É principalmente na educação formal que os sujeitos encontram situações pedagógicas destinadas à formação para a cidadania, o trabalho e o "pleno desenvolvimento do educando" - finalidades da educação nacional (BRASIL, 1996). Mas a escola não é o único lugar a contribuir com a formação pelos sujeitos. E tanto nela quanto nos demais espaços, importa a efetivação do direito de acesso às informações, que podem ser transformadas em conhecimentos pelos sujeitos no aprofundamento de sua leitura e ação no mundo ao longo da vida.

A ampliação do acesso à informação, e sua "qualidade", nos termos que serão discutidos neste trabalho, apresenta-se como questão-chave na formação permanente pelos portadores de deficiência auditiva que buscam ampliar sua criticidade e, para além de serem "incluídos", contribuírem com transformações sociais, econômicas, culturais em realidades que integram. Neste contexto de discussão, parte-se da compreensão de que a "informação significa formular e/ou codificar um determinado pensamento, vontade ou sensação" - sentido estrito do termo na teoria da informação, a partir da teoria matemática (HOHLFELDT, 2010, p. 690). Em linhas

\footnotetext{
${ }^{1}$ Cunha (2007, p. 63) define os surdos com "s" (minúsculo) como aqueles que se veem como deficientes auditivos e os Surdos (com "S” maiúsculo) que compartilham uma categoria cultural de autoidentificação.
}

\section{POLÊM!CA $\mid$ LABORE}

Polêmica - Revista Eletrônica da Uerj - Rua São Francisco Xavier, 524, $1^{\circ}$ andar bloco D, sl.1001 • Tels.: +55 21 2334-4088/4087 • http://www.e-publicacoes.uerj.br/index.php/polemica/index http://www.labore.uerj.br • laboreuerj@yahoo.com.br 
gerais, pode-se compreender informação como matéria-prima dos processos comunicacionais e, portanto, sua escassez impõe aos sujeitos dificuldades para manter relação com o seu entorno.

Este artigo apresenta uma discussão sobre a "qualidade" da acessibilidade à informação transmitida em Libras a partir de uma pesquisa bibliográfica (BRITO, 2018) sobre eventuais diferenças na emissão realizada por intérpretes e por surdos na literatura da área para, então, argumentar a favor da ampliação do repertório informacional pelos surdos para o desenvolvimento (permanente) de sua consciência crítica que, em Freire (1979, 2009), pode promover a transformação de si e de realidades que os impedem de "ser mais".

\section{Informação transmitida por legendas, intérpretes e surdos}

A Libras é um sistema linguístico que utiliza a percepção visual-espacial para emissão e recepção de mensagens; é expressada com o uso das mãos, das expressões faciais e do corpo para transmitir mensagens recebidas pelo surdo por meio da visão. Difere-se da língua de modalidade oral-auditiva, na qual o som é pronunciado pelo aparelho vocal e a audição é imprescindível para a compreensão das mensagens (QUADROS, 2004; RAMOS, 2013). A oficialização do uso e da difusão da Libras é, sobretudo, uma conquista de surdos que lutaram/lutam pelo seu reconhecimento como sujeitos com singularidades linguísticas. A prática da Língua de Sinais "está implicada na organização política da comunidade Surda e na reivindicação de sua especificidade" (GEDIEL, 2010, p. VIII).

$\mathrm{Na}$ Antiguidade, o surdo, por não falar a língua utilizada pelos ouvintes, chegou a ser considerado não humano, pois se acreditava que não tinha a capacidade de raciocínio. No decorrer dos séculos, as sociedades, majoritariamente de ouvintes, estigmatizaram os sujeitos surdos; nos "discursos sobre a surdez prevalecem as representações sociais subordinadas ao estereótipo da incapacidade e da deficiência do surdo" (WITKOSKI, 2010, p. 3).

Para o surdo "sinalizante" (QUADROS, 2017), a Língua de Sinais é "uma forma de comunicação e interação essencial para a apropriação de ideias e conceitos do universo" (CORRADI, 2007, p. 19), representando um papel expressivo na vida desse sujeito, “conduzindo-o, por intermédio de uma língua estruturada, ao desenvolvimento pleno" (DIZEU; CAPORALI, 2005, p. 588). Assim, a privação quanto ao uso da Libras poderia ser relacionada ao impedimento de "dizer a palavra" (FREIRE, 1981, p. 40), ou seja, ao direito de expressar-se e expressar o mundo, de criar e recriar, de decidir, de optar.

\section{POLÊM!CA $\mid$ LABORE}

Polêmica - Revista Eletrônica da Uerj - Rua São Francisco Xavier, 524, $1^{\circ}$ andar bloco D, sl.1001 • Tels.: +55 21 2334-4088/4087 • http://www.e-publicacoes.uerj.br/index.php/polemica/index http://www.labore.uerj.br • laboreuerj@yahoo.com.br 
No fim dos anos 1980, publicações direcionadas à comunidade surda denunciavam a “discriminação na acessibilidade às telecomunicações, à exclusão de pessoas surdas de filmes e programas de TV, e imagens estereotipadas dessas pessoas na mídia, entre outras" (PERLIN, 1998, p. 16-17). Infelizmente, em parte, a situação não mudou muito.

Após lutas para a legalização e o reconhecimento da Libras em 2002, os surdos brasileiros conquistaram o direito de uso dessa Língua em instituições de ensino - sejam elas especializadas ou não para deficientes auditivos -, em serviços públicos e de radiodifusão, a exemplo do que determina a Lei Brasileira de Inclusão da Pessoa com Deficiência (BRASIL, 2015). No entanto, no que tange à radiodifusão, contexto desta discussão, o também chamado Estatuto da Pessoa com Deficiência não obrigaria os serviços a transmitirem conteúdos em Libras:

\footnotetext{
Art. 67. Os serviços de radiodifusão de sons e imagens devem permitir o uso dos seguintes recursos, entre outros:

I - subtitulação por meio de legenda oculta;

II - janela com intérprete da Libras;

III - audiodescrição.
}

Tanto o artigo da Lei acima como o artigo 19 da Lei de Acessibilidade (BRASIL, 2000) teriam, em nosso entender, um caráter de promoção, não de obrigatoriedade do uso da Libras. Este último artigo determina, quase reproduzindo o anterior, que "os serviços de radiodifusão sonora e de sons e imagens adotarão planos de medidas técnicas com o objetivo de permitir o uso da linguagem de sinais ou outra subtitulação, para garantir o direito de acesso à informação às pessoas portadoras de deficiência auditiva". A redação do trecho "o uso da linguagem de sinais ou outra subtitulação" indicaria, também, que a inserção da legenda pode substituir a Libras.

Como será tratado adiante, entende-se que a inserção da legenda por si só não garantiria o acesso à informação pelos surdos analfabetos ou que não dominam a Língua Portuguesa. Valeria pontuar que mesmo parte dos sujeitos ouvintes e falantes do Português enfrentam dificuldades com essa língua, já que três em cada dez brasileiros são analfabetos funcionais, segundo o Indicador de Alfabetismo Funcional - Inaf de 2018 (INSTITUTO PAULO MONTENEGRO; AÇÃO EDUCATIVA, 2018).

Em geral, uma pessoa surda encontra restrições nos principais meios de difusão de informações. Pela questão auditiva, os surdos não têm acesso via rádio; se não dominam a

\section{POLÊM!CA $\mid$ LABORE}

Polêmica - Revista Eletrônica da Uerj - Rua São Francisco Xavier, 524, $1^{\circ}$ andar bloco D, sl.1001 • Tels.: +55 21 2334-4088 / 4087 • http://www.e-publicacoes.uerj.br/index.php/polemica/index http://www.labore.uerj.br・ laboreuerj@yahoo.com.br 
Língua Portuguesa, têm limitações quanto à mídia impressa - jornais, revistas etc.; também enfrentam dificuldades de acesso à mídia televisiva que, quase em sua totalidade, veicula programação com locução em Português. São poucas as situações em que os programas de TV ofertam o recurso de legendas (closed caption) ${ }^{2}$ ou recorrem a intérpretes na "janela de Libras" 3 , comumente conhecida como "janelinha". Por fim, na web, essas dificuldades impostas pela oralidade e a escrita também são encontradas.

Só em 2013, o Instituto Nacional de Educação de Surdos - INES, referência na área, iniciou as transmissões de programas pela Internet, sendo a primeira WebTV bilíngue - Libras e Português - no Brasil para surdos e ouvintes a não priorizar o recurso da "janelinha" de Libras. A TV INES seria um exemplo inédito no país de produção e veiculação de programas que exibem a presença de surdos utilizando Libras em primeiro plano na tela, ainda que também recorra a legendas e locução em Português ao mesmo tempo. A programação é produzida por uma equipe composta de profissionais de televisão surdos e ouvintes (INES, 2014). A TV INES oferece uma grade variada de caráter educativo: informação, cultura, entretenimento, esporte, documentários, desenhos animados, tecnologia, aulas de Libras, revistas eletrônicas, filmes com legendas descritivas e um talk show (programa de entrevista). O telejornal bilíngue "Primeira Mão", por exemplo, apresenta as "principais notícias" da semana do Brasil e do mundo, "contextualizando" as informações para o público surdo (INES, 2014).

O emprego de legendas e de "janelinhas" com intérpretes de Libras, por vezes encontrados em outras programações televisivas, seja via Internet, seja em canais sob concessão pública, foram conquistas importantes para o acesso à informação audiovisual pelos surdos. Porém, esses recursos apresentariam desafios a esse público, podendo prejudicar a compreensão do conteúdo veiculado.

Com relação à legenda, grande parcela dos surdos usuários de Libras não têm fluência oral e/ou escrita da Língua Portuguesa. Segundo Silva (2005, p. 43), "nota-se que um grande número de surdos, ao concluir sua escolarização básica, não é capaz de ler e escrever fluentemente ou de ter domínio sobre os conteúdos pertinentes a este nível de escolarização”. Siqueira e Silva $(2013$, p. 5) também consideram que "os surdos de nascença, por aprenderem

\footnotetext{
${ }^{2}$ Sistema de transmissão de legendas onde são incluídas referências textuais a respeito de músicas ou efeitos sonoros, para que pessoas com deficiência auditiva possam entender o que está acontecendo no programa em questão.

${ }^{3}$ Espaço delimitado no vídeo onde as informações veiculadas na língua portuguesa são interpretadas através da Libras, de acordo com o item 3.17 da Norma da ABNT NBR 15290/2005.
}

\section{POLÊM!CA | LABORË.}

Polêmica - Revista Eletrônica da Uerj - Rua São Francisco Xavier, 524, $1^{\circ}$ andar bloco D, sl.1001 • Tels.: +55 21 2334-4088/4087 • http://www.e-publicacoes.uerj.br/index.php/polemica/index http://www.labore.uerj.br • laboreuerj@yahoo.com.br 
a se comunicar primeiramente pela Libras (sua língua materna), têm grande dificuldade para aprender a língua portuguesa escrita". A relevância da Libras para surdos, segundo Ramos (2013, p. 22), “deve-se também ao fato de esses sujeitos perderem durante sua vida as informações passadas pela oralidade ou pela escrita, tão difícil para eles".

Assim, o uso de legendas em audiovisuais promoveria a perda pelos surdos de parte do conteúdo, mesmo os que dominam a Língua Portuguesa, pois, entre outras razões, há a necessidade de fazer a leitura de forma rápida por conta da velocidade em que as legendas são exibidas.

No que diz respeito às informações em Libras transmitidas por intérpretes, pode-se considerar, primeiramente, que o profissional costuma aparecer em segundo plano, ou seja, em tamanho reduzido e localizado em um dos cantos do vídeo, a “janelinha”. Por estar em um plano menor, a imagem do intérprete fica bastante reduzida, o que dificultaria aos surdos a visualização dos sinais de Libras com expressões faciais e movimentos do corpo dos profissionais. Também não seria fácil para os surdos acompanhar o intérprete concomitantemente com outras imagens, sendo dividida a atenção do telespectador.

De fato, o trabalho do intérprete vem permitindo a ampliação do acesso à informação pelos surdos. Trata-se de uma função complexa, pois não envolve somente a tradução de palavras, mas também interpretação de significados, “os quais as pessoas surdas podem entender como possuidoras de diferenças culturais que ultrapassem o mero processo de traduzir palavras faladas por gestos" (GEDIEL, 2010, p. 106). Haveria, portanto, diferenças entre o uso da Língua de Sinais por um nativo (pessoa surda) e por um ouvinte (intérprete). Segundo Marcon (2012), quando a interpretação é simultânea, ou seja, o intérprete não teve acesso prévio ao conteúdo, ela pode não ser suficiente para que o surdo compreenda o que está sendo transmitido, pois a tradução pode não corresponder ao discurso original.

Quadros (2004, p. 79) lembra-nos que "as palavras, as frases tomam significados que podem variar de acordo com os diferentes contextos e pessoas que participam do discurso". Guarinello, Santana, Figueiro e Massi (2008, p. 67) também sublinham que "a interpretação não é uma decodificação, como se o sentido estivesse na língua". As autoras entendem que ao se considerar um discurso como um efeito de sentido entre os interlocutores, fica evidenciado o quanto do intérprete está presente na interpretação. Ou seja, “entre uma língua e outra há um

\section{POLÊM!CA $\mid$ LABORE}

Polêmica - Revista Eletrônica da Uerj - Rua São Francisco Xavier, 524, $1^{\circ}$ andar bloco D, sl.1001 • Tels.: +55 21 2334-4088 / 4087 • http://www.e-publicacoes.uerj.br/index.php/polemica/index http://www.labore.uerj.br・ laboreuerj@yahoo.com.br 
sujeito que atribui sentidos em uma língua e tenta constituir sentidos em outra. Entende-se [...] que a linearidade da linguagem é uma ilusão" (GUARINELLO et al., 2008, p. 67).

Muitos intérpretes, às vezes, também não têm domínio do assunto que vão interpretar, seja por falta de acesso prévio ao material a ser interpretado ou, ainda, pela especificidade do tema, gerando a supressão, adição ou confusão de informações. Assim, o surdo, mesmo contando com o trabalho do intérprete, pode não ter acesso à mesma informação que os ouvintes (GUARINELLO et al., 2008). Segundo Quadros (2004, p. 80), "a fala é um processo dinâmico e a percepção do intérprete como passiva e neutra é um grande problema, pois este profissional está envolvido no processo".

A Língua de Sinais utiliza a visão, o espaço e é composta de "movimentos e formatos específicos das mãos, olhos, braços, face, cabeça e postura corporal, que combinados fornecem as características gramaticais necessárias para a formação de uma língua" (LIMA; BOECHAT; TEGA, 2003, p. 46); sendo necessário todo um trabalho de expressão facial e corporal que não se restringe ao uso das mãos. O intérprete, sendo intermediário entre o emissor e o receptor da mensagem, precisa captá-la em todas as suas nuances, como exemplos: a ênfase e/ou eloquência na voz do locutor, sua expressão facial ou um gesto corporal, sua emoção. Assim, nesse processo com a tríade locutor - intérprete - surdo, muito pode se perder. A transmissão de uma mensagem mais próxima de seu conteúdo original depende não só da técnica de interpretação, mas também da perspicácia e sensibilidade do intérprete, incluindo sua cultura, seus valores e compreensão de conceitos que podem influenciar a interpretação em Libras. Há, ainda, a questão da ética, da confiança, do controle emocional no momento da interpretação que, quando ausentes, podem ocasionar problemas tais como omissão, mal uso da expressão facial, equívocos de compreensão dos termos a serem traduzidos/interpretados, falta de domínio sobre o assunto, fatores esses que influenciam e distorcem a interpretação (SANTOS, 2006).

Muitos são os aspectos que envolvem a atividade do intérprete de Língua de Sinais, sugerindo-nos que uma informação transmitida de surdo para surdo seria mais próxima ao conteúdo original da mensagem e ao universo linguístico e cultural das comunidades Surdas. Reconhece-se que toda mensagem emitida por alguém que não a tenha produzido é interpretada. É o caso de surdo apresentador de telejornal a partir de uma notícia produzida por outro surdo (editor ou produtor). Algo se perde nessa interpretação, seja em Libras, em Língua Portuguesa e todas as demais, independente dos sujeitos. A partir da literatura analisada, entretanto,

\section{POLÊM!CA $\mid$ LABORE}

Polêmica - Revista Eletrônica da Uerj - Rua São Francisco Xavier, 524, $1^{\circ}$ andar bloco D, sl.1001 • Tels.: +55 21 2334-4088 / 4087 • http://www.e-publicacoes.uerj.br/index.php/polemica/index http://www.labore.uerj.br • laboreuerj@yahoo.com.br 
entende-se que as "perdas" seriam menores quando a interpretação for realizada por um surdo, em vez de um intérprete - neste caso, poderia haver prejuízo à acessibilidade à informação “original” por surdos telespectadores (BRITO, 2018).

Informação corresponde à matéria-prima a ser transformada em conhecimento, capaz de colocar o indivíduo em outro estágio de convivência consigo mesmo e com o mundo em que sua história se desenvolve (BARRETO, 1994). Disponibilizar informações em Libras não significa que efetivamente elas serão apreendidas e transformadas em conhecimento pelos surdos, principalmente se as "perdas" em relação ao conteúdo original influenciarem a compreensão da mensagem. Entretanto, infere-se que a inclusão social deles requer a ampliação desse acesso em Libras, de preferência, produzidas e transmitidas por surdos.

\section{Informação, Conscientização e "Inclusão"}

A ampliação do acesso às informações para e pelos surdos seria elemento fundamental para aqueles que desejam desenvolver sua consciência crítica e lutar por mudanças. Embora o acesso à um número crescente de informações pelos surdos não garanta maior autonomia e criticidade, sua restrição - em audiovisuais, contexto desta discussão - prejudicaria o processo de "conscientização" (FREIRE, 1979) daqueles sujeitos que a buscam, ironicamente, em uma época chamada de "era da informação" (CASTELLS, 1999). Para quem?

Surdos e ouvintes possuiriam a "vocação ontológica" (FREIRE, 2001) de almejar graus maiores de compreensão das realidades nas quais estão inseridos, desejo por modificar suas condições de existência e a de outros seres, transformar a si mesmo. Um processo que poderíamos aproximar do conceito de "conscientização" desenvolvido por Freire (1979) em outra época, mas que ainda hoje oferece subsídios para novas problematizações e reinvenções, mantendo-se atual.

Grosso modo ${ }^{4}$, pode-se compreender "conscientização" como um "processo permanente de reflexão crítica acompanhada por ação transformadora por meio da relação consciência-mundo que implica a utopia" (CARVALHO, 2017, p. 109). No processo de conscientização, sujeitos buscam ultrapassar a mera "tomada de consciência" (FREIRE, 1979,

\footnotetext{
${ }^{4}$ Trata-se apenas de uma breve aproximação do conceito que, para maior compreensão de sua complexidade, mereceria um espaço maior de exposição. Entretanto, tal procedimento extrapola os objetivos deste trabalho e recomenda-se para os interessados a leitura do original de Freire (1979) e, ainda, e o recente "Diálogo e práxis educativa: uma leitura crítica de Paulo Freire", de Carlos Alberto Torres, Edições Loyola (2014).
}

\section{POLÊM!CA $\mid$ LABORE}

Polêmica - Revista Eletrônica da Uerj - Rua São Francisco Xavier, 524, $1^{\circ}$ andar bloco D, sl.1001 • Tels.: +55 21 2334-4088 / 4087 • http://www.e-publicacoes.uerj.br/index.php/polemica/index http://www.labore.uerj.br • laboreuerj@yahoo.com.br 
p. 15) - um contato supérfluo com o objeto. "A conscientização implica, pois, que ultrapassemos a esfera espontânea de apreensão da realidade, para chegarmos a uma esfera crítica na qual a realidade se dá como objeto cognoscível e na qual o homem assume uma posição epistemológica” (FREIRE, 1979, p. 15). A realidade, no contexto deste trabalho, vai além daquelas nas quais o sujeito está, em um primeiro momento, imerso; também pode/poderia ser acessível por meio de informações disponibilizadas em Libras.

Como a realidade está em constante mudança, o processo de conscientização nunca se esgota porque, ao esclarecer uma questão, ela logo se apresenta como nova realidade. E, nesse sentido, compreende-se como um processo desenvolvido ao longo da vida por aqueles que buscam ampliar sua ação no mundo, motivados pela curiosidade:

\begin{abstract}
O processo de conscientização implica a superação da curiosidade ingênua pela crítica, também chamada por Freire (1996) de "curiosidade epistemológica". A "crítica", nesse caso, é uma qualidade atribuída ao substantivo "curiosidade", motor do processo de conhecimento, próprio da experiência vital, que se aperfeiçoa na existência do mundo e vai sendo histórica e socialmente construída e reconstruída. Não há uma ruptura entre a curiosidade ingênua e a crítica, nem uma passagem automática, mas uma superação. A diferença estaria na rigorosidade metódica durante o estudo do objeto, do qual se toma distância para dele se aproximar e "falar prudentemente" (CARVALHO, 2017, p. 110).
\end{abstract}

Para "falar prudentemente" (FREIRE, 2001, p. 55), seria necessário que os surdos tivessem acesso diversificado às informações e que estas fossem mais próximas do conteúdo original de produção da mensagem. Assim, podem fundamentar melhor suas opiniões, expressar com mais criticidade e atuar como seres históricos. Os surdos "constroem sua autonomia ao se situarem melhor diante de uma realidade ou campo problemático, pois têm a leitura do mundo ampliada" (LOPES; GOETTERT, 2015, p. 364).

Não se ignora que conteúdos emitidos tanto em uma conversa cotidiana quanto pelas mídias carregam ideologias que podem corroborar para a manutenção das muitas formas de opressão. Entretanto, a restrição a elas tende a circunscrever a realidade à vivida pelo sujeito e/ou retratada apenas por pessoas conhecidas. Considera-se, nesta reflexão, sobretudo, os surdos que não dominam a Língua Portuguesa e que possuem acesso à poucas fontes de informação; em geral, parentes e amigos que usam a Libras.

A mera ampliação das oportunidades de acesso às informações em Libras também não significa que surdos as utilizem para problematizar suas condições de vida e o mundo no qual vivem. Mas seria preciso reconhecer, em um primeiro momento, que grande parte das

\title{
POLÊM!CA $\mid$ LABORE
}

Polêmica - Revista Eletrônica da Uerj - Rua São Francisco Xavier, 524, $1^{\circ}$ andar bloco D, sl.1001 • Tels.: +55 21 2334-4088 / 4087 • http://www.e-publicacoes.uerj.br/index.php/polemica/index http://www.labore.uerj.br・ laboreuerj@yahoo.com.br 
informações que nos ajudam a problematizar questões do cotidiano são obtidas por intermédio de diversos veículos (notícias, artigos, filmes etc.) e não pelo acesso direto às múltiplas realidades.

Assim como a minoria analfabeta seria oprimida em uma sociedade cuja maioria é alfabetizada, também os surdos, minoria linguística numa sociedade de ouvintes que se expressa por uma língua oral, são “[...] submetidos aos mitos da cultura dominante, entre eles o de sua 'natural inferioridade', não percebem, quase sempre, a significação real de sua ação transformadora sobre o mundo" (FREIRE, 1981, p. 41). Nesse sentido, parece-nos que o acesso maior às informações pelo surdo, somado a um processo de conscientização por ele desenvolvido, caminha em direção à superação da ideia de que os surdos são sujeitos a serem incluídos na sociedade.

A esse respeito, cabe uma breve consideração, uma vez que essa expressão perpassa muitas discussões sobre surdez. Entende-se que, em um primeiro momento, não caberia tratar os surdos como "excluídos" a serem "incluídos" na sociedade. Primeiro porque o termo "exclusão social" - de onde derivam outros usos - é problemático; sob o guarda-chuva da "exclusão" tudo e todos caberiam. Tem-se que a expressão teria surgido no âmbito das Ciências Humanas e Sociais na década de 1970, em meio às discussões acerca de bolsões de grande pobreza, e ao longo do tempo passou a ser empregada com diferentes graus e formas de exclusão (DORTIER, 2010).

Em segundo lugar, o emprego da palavra exclusão e, portanto, de seu oposto - inclusão - prevê a existência de um "fora"; mas, de fato, não existe um "fora" da sociedade. Os surdos fazem "parte de" sociedades cujo sistema os oprime, não oferece condições para "serem mais" (FREIRE, 2009). Talvez a expressão “marginalizados” lhes coubesse, mas, a partir de uma das perspectivas adotadas nesta reflexão, o uso da palavra também não seria adequado:

Como marginalizados, "seres fora de" ou "à margem de", a solução para eles estaria em que fossem "integrados", "incorporados" à sociedade sadia de onde um dia "partiram", renunciando, como trânsfugas, a uma vida feliz...

Sua solução estaria em deixarem a condição de ser "seres fora de" e assumirem a de "seres dentro de".

Na verdade, porém, os chamados marginalizados, que são os oprimidos, jamais estiveram fora de. Sempre estiveram dentro de. Dentro da estrutura que os transforma em "seres para outro". Sua solução, pois, não está em "integrar-se", em "incorporarse" a esta estrutura que os oprime, mas em transformá-la para que possam fazer-se "seres para si" (FREIRE, 1987, p. 35, grifos do autor).

\section{POLÊM!CA $\mid$ LABORE}

Polêmica - Revista Eletrônica da Uerj - Rua São Francisco Xavier, 524, $1^{\circ}$ andar bloco D, sl.1001 • Tels.: +55 21 2334-4088 / 4087 • http://www.e-publicacoes.uerj.br/index.php/polemica/index http://www.labore.uerj.br・ laboreuerj@yahoo.com.br 
As lutas pela transformação das estruturas opressoras, portanto, não seriam realizadas "a parte, fora" do sistema, mas em seu interior, porque, pela mesma razão, não existe um "fora". As mudanças (de si e do mundo, com os outros) são empregadas por aqueles que buscam "ser mais" - portanto, nem todos os sujeitos - dentro do próprio sistema. O uso corrente da palavra “inclusão" em discussões sobre surdez, não poderia se referir à pura incorporação ao sistema se partir de uma perspectiva crítica, como a freiriana. Mas visar, em última instância, transformar a estrutura opressora para que os surdos "possam fazer-se 'seres para si"” (FREIRE, 1987, p. 35).

\section{Considerações finais}

É salutar ao ser humano a busca por informações, por conhecer, para saciar a curiosidade. Essa curiosidade é inerente ao homem, que procura esclarecimento, inquieta-se, move-se, constitui-se como ser criativo. Entretanto, para muitos sujeitos, como os pertencentes às comunidades Surdas, é negado o acesso à maioria das informações, ainda que a Libras seja respaldada pela legislação em algumas situações. "A comunicação torna-se autoritária na medida em que impede que os fatos e acontecimentos ocorridos em uma sociedade sejam acessíveis a todos" (FILHO, 2010, p. 368). Nesse sentido, a acessibilidade por meio da Libras torna-se elemento-chave no processo de "conscientização" (FREIRE, 1979) ao longo da vida por surdos que anseiam lutar contra as diversas formas de opressão a que são submetidos todos os dias.

A ampliação da acessibilidade em Libras integra essa luta, sejam as informações em Libras veiculadas por intérpretes, sejam por surdos. Entretanto, o levantamento na literatura da área nos sugere que uma informação transmitida de surdo para surdo estaria mais próxima do universo linguístico e cultural das comunidades Surdas. Além disso, que as "perdas" no processo de interpretação em relação ao conteúdo original seriam menores quando realizadas por um surdo, em vez de um intérprete, podendo, nesse sentido, gerar prejuízo à acessibilidade à informação "original” por surdos telespectadores. Há de se considerar, ainda, que o envolvimento de surdos na produção e transmissão de informações acaba por integrar processos de democratização da comunicação.

Uma das lutas pela "inclusão" de surdos, nos termos aqui discutidos, certamente passa pela ampliação da acessibilidade de informações em Libras - de preferência, produzidas e

\section{POLÊM!CA $\mid$ LABORE}

Polêmica - Revista Eletrônica da Uerj - Rua São Francisco Xavier, 524, $1^{\circ}$ andar bloco D, sl.1001 • Tels.: +55 21 2334-4088 / 4087 • http://www.e-publicacoes.uerj.br/index.php/polemica/index http://www.labore.uerj.br・ laboreuerj@yahoo.com.br 
transmitidas por surdos - e pelo aproveitamento desse "insumo" para maior criticidade e lutas desses sujeitos.

\section{Referências}

BARReto, A. A. A questão da informação. Revista São Paulo em Perspectiva. São Paulo, v. 8, n. 4, p. 3-8, out./dez. 1994. Disponível em: http://produtos.seade.gov.br/produtos/spp/v08n04/v08n04_01.pdf. Acesso em: 7 jan. 2017.

BRASIL. Lei n ${ }^{\circ}$ 9.394, de 20 de dezembro de 1996. Estabelece as diretrizes e bases da educação nacional. Diário Oficial da União, Brasília, DF, 23 dez. 1996. Seção 1, p. 27833. Disponível em: http://www.planalto.gov.br/ccivil_03/leis/L9394.htm. Acesso em: 2 abr. 2016.

Lei $\mathrm{n}^{\circ} 10.098$, de 19 de dezembro de 2000. Estabelece normas gerais e critérios básicos para a promoção da acessibilidade das pessoas portadoras de deficiência ou com mobilidade reduzida, e dá outras providências. Diário Oficial da União, Brasília, DF, 20 dez. 2000. Seção 1, p. 2. Disponível em: http://www4.planalto.gov.br/legislacao/ legislacao-1/leis-ordinarias/legislacao-1/leis-ordinarias/2000\#content. Acesso em: 2 abr. 2016.

. Lei $\mathrm{n}^{\circ} 10.436$, de 24 de abril de 2002. Dispõe sobre a Língua Brasileira de Sinais - Libras e dá outras providências. Diário Oficial da União, Brasília, DF, 25 abr. 2002. Seção 1, p. 23. Disponível em: http://www4.planalto.gov.br/legislacao/legislacao-1/leis-ordinarias/legislacao-1/leis-ordinarias/2002\#content. Acesso em: 2 abr. 2016.

Lei no 13.146, de 6 de julho de 2015. Institui a Lei Brasileira de Inclusão da Pessoa com Deficiência (Estatuto da Pessoa com Deficiência). Diário Oficial da União, Brasília, DF, 7 jul. 2015. Seção 1, p. 2. Disponível em: http://www.planalto.gov.br/ccivil_03/_Ato2015-2018/2015/Lei/L13146.htm. Acesso: em 2 abr. 2016.

BRITO, R. de C. M. C. Da janelinha para o janelão: relevância da primeira WebTV bilíngue português/libras TV INES - para o acesso à informação e à criticidade dos surdos. 2018. 191 f. Dissertação (Mestrado em Educação) - Programa de Pós-Graduação em Educação, Universidade Estácio de Sá, Rio de Janeiro, 2018.

CAMPELlO, A. R. S. Pedagogia Visual na Educação de Surdos-Mudos. 2008. 166 f. Tese (Doutorado em Educação) - Programa de Pós-Graduação em Educação, Universidade Federal de Santa Catarina, Florianópolis, 2008. Disponível em: http://www.cultura-sorda.org/wp-content/uploads/2015/04/TesisSouzaCampello2008b. pdf. Acesso em: 28 mar. 2016.

CORRADI, J. A. M. Ambientes informacionais digitais e usuários surdos: questões de acessibilidade. 2007. 214 f. Dissertação (Mestrado em Ciência da Informação) - Faculdade de Filosofia e Ciências, Universidade Estadual Paulista, Marília, 2007. Disponível em: http://repositorio.unesp.br/handle/11449/93697. Acesso em: 28 mar. 2016.

CARVALHO, J. Uma concepção de cidadania (planetária) para formação cidadã. Revista Inter Ação, v. 42, n. 1, p. 105-121, jan./abr. 2017. DOI: https://doi.org/10.5216/ia.v42i1.44516.

CASTELLS, M. A sociedade em rede. In: A era da informação: economia, sociedade e cultura. São Paulo: Paz e Terra, 1999. V. 1.

DIZEU, L. C. T. D.; CAPORALI, S. A. A língua de sinais constituindo o surdo como sujeito. Revista Educação e Sociedade, Campinas, v. 26, n. 91, p. 583-597, maio/ago. 2005. Disponível em: http://www.scielo.br/pdf/es/v26n91/a14v2691.pdf. Acesso em: 28 jan. 2017.

\section{POLÊM!CA $\mid$ LABORE}

Polêmica - Revista Eletrônica da Uerj - Rua São Francisco Xavier, 524, $1^{\circ}$ andar bloco D, sl.1001 • Tels.: +55 21 2334-4088 / 4087 • http://www.e-publicacoes.uerj.br/index.php/polemica/index http://www.labore.uerj.br • laboreuerj@yahoo.com.br 
DORTIER, J.-F. Exclusão. In: 2010.

Dicionário de ciências humanas. São Paulo: WMF Martins Fontes,

FREIRE, P. Conscientização: teoria e prática da libertação - Uma introdução ao pensamento de Paulo Freire. São Paulo: Cortez e Moraes, 1979.

Ação cultural para a liberdade e outros escritos. 5. ed. Rio de Janeiro: Paz e Terra, 1981.

Pedagogia do oprimido. 17. ed. Rio de Janeiro: Paz e Terra, 1987.

2001.

Pedagogia da autonomia: saberes necessários à prática educativa. 25. ed. São Paulo: Paz e Terra,

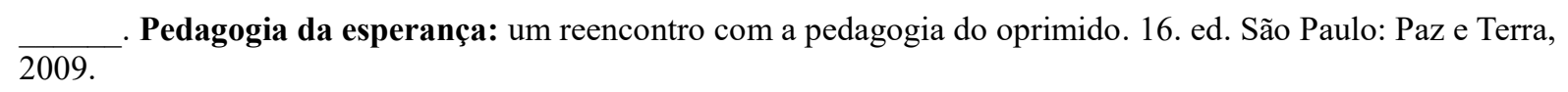

GEDIEL, A. L. B. Falar com as mãos e ouvir com os olhos?: a corporificação dos sinais e os significados dos corpos para os surdos de Porto Alegre. 292 f. Tese (Doutorado em Antropologia Social) - Instituto de Filosofia e Ciências Humanas, Universidade Federal do Rio Grande do Sul, Porto Alegre, 2010. Disponível em: http://hdl.handle.net/10183/78198. Acesso em: 28 mar. 2016.

GUARINELLO, A. C.; SANTANA, A. P.; FIGUEIRO, L. C.; MASSI, G. O intérprete universitário da Língua Brasileira de Sinais na cidade de Curitiba. Revista Brasileira de Educação Especial, Marília, v. 14, n. 1, jan./abr. 2008. Disponível em: http://www.scielo.br/scielo.php?script=sci_arttext\&pid=S141365382008000100006. Acesso em: 4 fev. 2017.

FILHO, L. L. L. Democratização da comunicação. In: SOCIEDADE BRASILEIRA DE ESTUDOS INTERDISCIPLINARES DA COMUNICAÇÃ̃. Enciclopédia INTERCOM de comunicação. São Paulo: INTERCOM, 2010. V. 1.

HOHLFELDT, A. Informação. In: SOCIEDADE BRASILEIRA DE ESTUDOS INTERDISCIPLINARES DA COMUNICAÇÃO. Enciclopédia INTERCOM de comunicação. São Paulo: INTERCOM, 2010. V. 1.

IBGE - INSTITUTO BRASILEIRO DE GEOGRAFIA E ESTATÍSTICA. Censo Demográfico 2010. Disponível em: http://www.ibge.gov.br/apps/snig/v1/?loc=0\&cat=-1,-2,-3,128\&ind=4643. Acesso em 29 abr. 2016.

INES - INSTITUTO NACIONAL DE EDUCAÇÃO DE SURDOS. Revista Espaço. Edição Comemorativa dos 140 anos. Rio de Janeiro: Instituto Nacional de Educação de Surdos, MEC, 1997.

2017.

Sobre a TV INES. TV INES. Disponível em: http://tvines.org.br/?page_id=33. Acesso em: 29 mar.

INSTITUTO PAULO MONTENEGRO; AÇÃO EDUCATIVA. INAF Brasil 2018: resultados preliminares. Disponível em: http://acaoeducativa.org.br/blog/publicacoes/indicador-de-alfabetismo-funcional-inaf-brasil2018/. Acesso em: 19 nov. 2018.

LIMA, M. C. M. P.; BOECHAT, H. A.; TEGA, L. M. Habilitação Fonoaudiológica da Surdez - Uma experiência no CEPRE/FCM/Unicamp. In: SILVA, I. R.; KAUCHAKJE, S.; GESUELI, Z. M. (Org.). Cidadania, surdez e linguagem: desafios e realidades. São Paulo: Plexus, 2003, p. 41-49.

LOPES, D. de Q.; GOETTERT, N. Tecnologias digitais e estratégias comunicacionais de surdos: a inclusão digital numa perspectiva bilíngue. Revista Educação, Porto Alegre, v. 38, n. 3, p. 358-368, set./dez. 2015. Disponível em: http://revistaseletronicas.pucrs.br/ojs/index.php/faced/article/view/21780/14110. Acesso em: 27 mar. 2016.

\section{POLÊM!CA $\mid$ LABORE}

Polêmica - Revista Eletrônica da Uerj - Rua São Francisco Xavier, 524, $1^{\circ}$ andar bloco D, sl.1001 • Tels.: +55 21 2334-4088 / 4087 • http://www.e-publicacoes.uerj.br/index.php/polemica/index http://www.labore.uerj.br・ laboreuerj@yahoo.com.br 
MARCON, A. M. O papel do tradutor/intérprete de libras na compreensão de conceitos pelo surdo. ReVEL, v. 10, n. 19, p. 233-249, 2012. Disponível em: http://www.revel.inf.br/files/644681b81f2cb7f90f93b613729ef637.pdf. Acesso em: 28 fev. 2017.

PERLIN, G. Histórias de vida surda: Identidades em questão. 1998. 51f. Dissertação (Mestrado em Educação) - Faculdade de Educação, Universidade Federal do Rio Grande do Sul, Rio Grande do Sul, 1998.

QUADROS, R. M. O tradutor e intérprete de língua brasileira de sinais e língua portuguesa. Brasília: MEC; SEESP; Programa Nacional de Apoio a Educação de Surdos, 2004. Disponível em: http://portal.mec.gov.br/seesp/arquivos/pdf/tradutorlibras.pdf. Acesso em 27 fev. 2017.

Língua de herança: Língua Brasileira de Sinais. Porto Alegre: Penso, 2017.

RAMOS, M. I. B. B. Audiovisual em Libras: os sentidos construídos por professores sobre o vídeo "sinalizando a Sexualidade". 2013. 132 f. Dissertação (Mestrado em Educação em Ciências e Saúde) - Centro de Ciências da Saúde, Universidade Federal do Rio de Janeiro, Rio de Janeiro, 2013. Disponível em: https://br.123dok.com/document/yd2jomeq-maria-ines-batista-barbosa-ramos-audiovisual-em-libras-os-sentidosconstruidos-por-professores-sobre-o-video-sinalizando-a-sexualidade.html. Acesso em: 20 mar. 2016.

SANTOS, B. A construção multicultural da igualdade e da diferença. Oficina do CES, n. 135, jan. 1999. Coimbra: Centro de Estudos Sociais - CES, 1999. Disponível em:

http://www.ces.uc.pt/publicacoes/oficina/135/135.pdf. Acesso em: 20 mar. 2016.

SILVA, A. C. A representação social da surdez: entre o mundo acadêmico e o cotidiano escolar. In: FERNANDES, E. (Org.). Surdez e bilinguismo. Porto Alegre: Editora Mediação, 2005.

SIQUEIRA, A. C. B.; SILVA, C. P. Dar voz a quem não é ouvido: barreiras enfrentadas pelo surdo no acesso à informação televisiva. Cadernos da Escola de Comunicação do Centro Universitário Unibrasil - Edição Especial: Anais IX Ciclo de debates sobre jornalismo da Unibrasil, Paraná, 2013. Disponível em: http://revistas.unibrasil.com.br/cadernoscomunicacao/index.php/comunicacao/article/view/123. Acesso em: 03 mar. 2017.

WITKOSKI, S. A. Problematizando a ideologia oralista. Revista Virtual de Cultura Surda, Rio de Janeiro, n. 6, set. 2010. Arara Azul. Disponível em: http://editora-arara-azul.com.br/site/edicao/70. Acesso em: 09 jul. 2016.

Recebido em: 12/03/2019.

Aceito em: 30/05/2019.

\section{POLÊM!CA $\mid$ LABORE}

Polêmica - Revista Eletrônica da Uerj - Rua São Francisco Xavier, 524, $1^{\circ}$ andar bloco D, sl.1001 • Tels.: +55 21 2334-4088 / 4087 • http://www.e-publicacoes.uerj.br/index.php/polemica/index http://www.labore.uerj.br • laboreuerj@yahoo.com.br 